\title{
IS A CLASS APPROACH TO LEARN HISTORY OUT OF DATE? OR ... (INVITATION TO A DISCUSSION)
}

(C) 2019

Ippolitov Georgiy Mikhailovich, doctor of historical sciences, professor of Philosophy Department Povolzhskiy State University of Telecommunications and Informatics (Samara, Russian Federation)

Abstract. In the following paper the author disclosures some aspects of a complex problem. It is a class approach to the assessment of events and phenomena as one of the approaches to learn history. The style is lapidary, with conciseness elements. The author considers fundamental postulates of the Marxist-Leninist concept of a class approach to the assessment of events and phenomena as one of the approaches to learn history. The emphasis is placed here on Lenin's understanding of the methodological phenomenon stated above and its development by ideologists of the Communist Party governing the Soviet state. Development of the studied concept in the Soviet historical science is traced. At the same time it is emphasized that eclecticism elements were allowed when scientists confused the concepts «principles of a historical research» and «approaches to learn history». The author considers how the problem of a class approach to assessment of events and phenomena is treated in a Post-Soviet and modern historiography. The author says that this approach hasn't become outdated in historical science as many representatives of so-called liberal historical school consider (don't confuse with V.O. Klyuchevsky) and continues to function. However, it changed manifestation forms and receded a little into the background.

Keywords: class approach; K. Marx; F. Engels; V.I. Lenin; soviet historical science; Marxism-Leninism; social approach; game of definitions.

УДК 930.1

DOI 10.24411/2309-4370-2019-12234

Статья поступила в редакцию 22.01.2019

\section{ТРАНСФОРМАЦИИ ОЦЕНОК ИСТОРИЧЕСКИХ СОБЫТИЙ И ФАКТОВ В КОНТЕКСТЕ СОЦИОКУЛЬТУРНОГО ВЛИЯНИЯ СОВРЕМЕННОСТИ}

(C) 2019

Ипполитова Анастасия Георгиевна, кандидат культурологии, доцент, профессор кафедры философии и общегуманитарных дисциплин Самарский юридический институт ФСИН России (2. Самара, Российская Федераџия)

Аннотация. В статье показаны трансформации отношения к историческим событиям, фактам и персоналиям в контексте влияния парадигм мышления современной социокультурной обстановке. Объективность исторической науки - вещь подвижная, ведь сама история - органичная часть культуры, отражающая в своих интерпретациях её менталитет и ценностные ориентации, важные для социума в данный отрезок времени. Исторический процесс - живой культурный поток, наполненный уникальными знаками и символами, способами демонстрации в культуре. Современность определяет отношение общества к историческому процессу, значимость персоналий, их популярность. Здесь историческая оценка становится отражением современных реалий. Мы не можем во всей полноте ощутить на себе влияния исторического персонажа, только вообразить. Примеряем на себя образы прошлого, немного фантазируем, наделяем эмоциями и чувствами, «включая» субъективность восприятия исторических событий в современности. Общество проводит исторические параллели, оценивает прошлое с позиции понятной ему парадигмы мышления, что и приводит к трансформации исторических оценок в различные исторические периоды. Все сказанное выше, безусловно, характерно для трансформационного процесса отечественной истории, что показано на ряде примеров. Они отражают не позицию автора, а именно интерпретацию, характерную для современного социума. Особое внимание уделено оценке Великой Отечественной войны, память о которой необходима для укрепления единства общества и трансляции патриотических ценностей.

Ключевые слова: история; культура; кризис культуры; объективность исторической науки; историческая персоналия; историческое событие; социокультурная трансформация; миф; мифологизация истории; парадигма мышления; К. Леви-Стросс; Т. Лессинг; Великая Отечественная война; монголо-татары; И.В. Сталин; Николай II.

История - наука, которой должна быть присуща объективность, строгий подход. Одновременно это очень гибкая форма знания, на которую накладывает отпечаток современность и ее ценностные установки, социальная обстановка и массовые суждения. Иными словами, культура конкретного отрезка времени, ментальность социумов оказывает непосредственное влияние на оценку исторических событий и фактов. В таком смысле история предстает перед нами феноменом культуры, ее органической частью. А содержание и смысл исторического процесса при- вносится интерпретаторами истории [1, с. 283]. В повседневности она ассоциируется с воспоминаниями, которые необходимы любому. Еще К. Леви-Стросс заметил «Воспоминание - великое наслаждение для человека, но только не тогда, когда оно оказывается буквальным» [2, с. 83-84]. Однако именно в процессе воспоминаний и обнаруживается опасность трактовать историю буквально, перенося на нее картину мира современности и личные пристрастия. Здесь и обнаруживаются трансформации интерпретаций и частичная потеря объективного взгляда. 
Ипполитова А.Г.

Собственно говоря, в различных культурных картинах мира историческая оценка может содержать кардинально разные интерпретации и даже наполнение $[1$, с. 283]. Выражение оценочного суждения строится на основе разных акцентов, выраженных в знаковых конструктах исторической реальности. При этом в современности может одномоментно существовать несколько, условно говоря, «исторических процессов», появившихся вследствие различных трактовок (с позиций разных социальных, национально-религиозных, возрастных, политических и прочих групп и даже научных школ).

Осознание такой специфики интерпретации истории приходит в методологию исторической науки в XX веке, что выглядит закономерным. Вызовы истории этого столетия оказались для мирового исторического процесса эпохально-кризисными и революционно-модернистскими одновременно. Кардинальное изменение мышления человека вообе приводит к уникальным трансформациям в оценке истории как таковой. Появляются инновационные взгляды О. Шпенглера, Н. Данилевского, Л.Н. Гумилёва, Школы «Анналов», Т. Лессинга [3-9] и многих других.

От классической оценки событий и фактов истории ученых XX столетия отличает восприятие исторического процесса как живого культурного потока, наполненного уникальными для своей эпохи оболочками, способами демонстрации, но едиными в своей сути, подчиненными универсальным законам развития культуры. Уместно привести суждения Лессинга, который рассматривал сущность исторического познания как миф, придание смысла бессмысленному [1, с. 401]. Конечно, такое восприятие весьма дискуссионно, но нельзя не согласиться, что историческая интерпретация - живая мысль, на которую накладывает отпечаток современная парадигма мышления. Здесь всегда присутствует мифотворчество эпохи. Сам Лессинг посвятил научно-общественную деятельность борьбе с деструктивной идеологией нацистского Третьего рейха, спекулятивной мифологизации истории и культуры в этом государстве [9]. А деструктивное мифотворчество нацистской культуры вряд ли вызывает сомнения [10-12].

История, безусловно, мифологична. Но приведенный выше пример показывает не трансформации, а деформации. Ведь трансформационный процесс мифологизации истории объективен в контексте понимания, что миф и мифологическое мышление - базовый элемент структуры любой культуры, что было доказано К. Леви-Строссом, который констатировал, что любой миф объясняет, каким образом определенная цель была достигнута столь же определенными средствами» [2, с. 341]. История необходима как ретранслятор мысли и опыта человечества, способ усвоения духовных ценностей: «История не производит бесполезных событий» [2, с. 343]. Однако, с другой стороны, общество вкладывает смыслы современности в оценку прошлого, рассматривает их «со своей колокольни» через стереотипы мышления, а также проводит параллели, выражая суждения через символизм и знаки эпохи.

Таким образом, объективность исторической науки - вещь подвижная, ведь история существует не только в научном поле, но и в образовательном, в искусстве и его образах, духовно-религиозных осноСамарский научный вестник. 2019. Т. 8, № 2 (27) вах культуры, обывательских представлениях и пр. Последние отражают стереотипные суждения и актуальные для социума факты события прошлого сегодня.

Иными словами, современность определяет отношение общества к историческому процессу, значимость персоналий. При этом в оценке последних особенно активно проявляется мифологичность истории. Ведь объективность в оценке деятелей истории «требует» определения их четкой роли, как в легенде или сказке: добрый или злой, герой или антигерой, друг или враг и т.д. А искусство, литературное творчество, обыденное сознание и вовсе отталкивается от личных или коллективных симпатий, как при знакомстве с обычным современником. Например, если исторический герой симпатичен, то не важно, совершал он или нет деструктивные поступки. Ведь историческая оценка становится отражением современных реалий. Мы не можем во всей полноте ощутить на себе влияния исторического персонажа, только вообразить. Примеряем на себя образы прошлого, немного фантазируем, наделяем эмоциями и чувствами, «включая» субъективность восприятия исторических событий в современности.

Всё сказанное выше, безусловно, характерно для трансформационного процесса в отечественной истории, что можно показать на ряде примеров. Следует подчеркнуть, что в данной статье предлагается не отношение или позиция автора, а интерпретация, характерная для современной культуры. Обозначена общая тенденция в трансформации исторического процесса. Примеры разделены на две категории: взгляд на события и взгляд на персоналии.

Наиболее яркую и социально действенную интерпретацию истории, необходимую для формирования ценностей современного человека, мы наблюдаем вокруг оценок трагических и героических событий Великой Отечественной войны (1941-1945 гг.). Здесь наблюдается тенденция к продолжению и укреплению суждений предшествующих поколений. Здесь нет случайности. Данное эпохальное событие сегодня - конструктивный миф, одна из цементирующих российский социум ценностей. Великая Отечественная война для нас - «битва титанов». Священная война - источник силы для современного человека. Поэтому оценки нескольких предшествующих поколений кардинально не отличаются. Тем более, что данная история практически каждой семьи с личными переживаниями. Герои - образцы, идеалы и, в прямом смысле слова, наши предки. Не случайно укрепляется такое уникальное социокультурное явление, ставшее уже полем для осмысления ученых всех социогуманитарных наук как Бессмертный полк. Здесь очевидна уникальная трансформационная сила мифологизации истории. Бессмертный полк из простой культурной акции памяти превратился в самоорганизующуюся тенденцию, укрепился в момент внешнеполитического кризиса, в период угрозы нашей коллективной идентичности. Миф как ядро культурной структуры играет в данном случае спасательную роль. Спасение же необходимо от влияния постсоветской действительности с псевдодемократией и аморфными ценностями, в которых «растерялись» базовые мифологемы, дающие ощущение стабильности и перспектив будущего. Бессмертный полк - типичный мощный мифологичный ритуал, 
коллективная молитва предкам, через которую мы обращаемся к архетипическим слоям личной и коллективной души общества.

Исследовательский потенциал темы Великой Отечественной войны настолько огромен, что именно по этой причине вокруг него столько спекуляций и псевдолиберальных трактовок, заставляющих военных историков развернуть активную научную борьбу с фальсификаторами всех оттенков и мастей [13-15]. В качестве иллюстрации попыток нивелировать важный социокультурный и морально-психологический опыт войны можно напомнить такие суждения: «панфиловцев не было, Зоя Космодемьянская - фанатичка, не совершавшая подвигов, советский солдат - мародер, мучивший несчастных немцев, а немцы страдальцы и пр.».

Однако социум такие оценки не принимает, осуждает или игнорирует. Общая тенденция позитивна, что доказывает популярность движения реконструкторов, которое в нашей стране особенно мощно развивается именно вокруг событий Великой Отечественной. Активную патриотическую работу осуществляет движение поисковиков. Данные две полноценные субкультуры, влияющие на развитие патриотической культуры, укрепились в массовом сознании и повседневности. Если говорить о культурно-символическом смысле их действий, то они замыкают цепь между предками и потомками, регламентируют через ритуал веру в жизнь предков за чертой. Необходимо подобное именно потомкам. Если общество утратит влияние мифа о предках и вместе с ним культ, оно станет «реликтом». Ещё один уникальный пример, доказывающий факт конструктивной сакрализации событий Великой Отечественной войны, - художественный фильм «Двадцать восемь панфиловцев» (реж. Шальопа А., Дружинин К., 2016 г.), который полностью снят на средства обычных людей.

Автор статьи рискнет предположить, что популярность истории войны будет только увеличиваться, что связано с ростом популярности и идеализации советского прошлого и коммунистической идеологи. Это не случайно, поскольку современная внутриполитическая и социальная реальность представляет системный кризис и внутренний хаос на фоне коррупции, безработицы и «первобытного» капитализма. Независимо от наших современных политических симпатий и предпочтений, следует признать факт, что непобедимая сила духа Советского Солдата была сформирована коммунистической идеологией и вообще парадигмой мышления той эпохи с ценностями свободы, равенства и братства, а также социальной ответственности на всех уровнях социальной стратификации.

Несколько иная ситуация складывается вокруг темы восстания декабристов. В современных российских реалиях давать им такие же яркие и однозначные оценки невозможно. Поэтому историки, деятели культуры, искусства и др. деликатно молчат. Романтики и герои советской историографии, отечественной литературы, кинематографа и прочие сакрализированы и мифологизированы в советский период. Достаточно вспомнить художественный фильм «Звезда пленительного счастья» (реж. Мотыль Я.Д., 1975 г.), демонстрирующий высокие идеалы чести, достоинства, самоотверженности русского дворянства и офицерства. Священным статусом были наделены казненные декабристы: П.И. Пестель, К.Ф. Рылеев, С.И. Муравьев-Апостол, М.П. Бестужев-Рюмин, П.Г. Каховский.

Что сегодня заставляет практически обходить тему декабристского восстания? Для страны, пережившей революцию, гибель советской империи, локальные войны и «нашествие» экстремизма, данная тема - острый угол, способный развернуть масштабные конфликтные дискуссии (даже в школьной аудитории).

Действительно, декабристы - благороднейшие личности, несомненные герои 1812 года, лучшие дворяне, осознавшие цивилизационную пропасть в развитии России и передового для XIX века западного мира. Но современный молодой человек, который вырос в эпоху терроризма и экстремизма, трудно понимает, почему бунтовщики стали героями. А представителям социальных групп, имеющих отношение к военной субкультуре, сложно объяснить: как офицера, пренебрегшего присягой, можно оценивать позитивно. В глазах советского военного они попытались свергнуть тирана, так как монархия - априори зло, мешающее Отечеству и народу. Между тем сегодня наше отношение к царской власти кардинально иное. А человеком интеллигентным и грамотным замечаются и вовсе противоречивые моменты событий, развернувшихся на Сенатской площади. В частности, за что убит генерал М.А. Милорадович? Не коррумпированный, кстати, генерал, что особенно привлекает наших современников. Герой 1812 года, призывавший к долгу и чести, верности государю и присяге. Декабристы же изначально заклеймили Николая I как бездарного правителя, хотя он не успел предпринять ни одного действия в качестве монарха. История заставила его принимать первые эпохальные решения в отношении бунтовщиков и «вчерашних» друзей. В прямом смысле слова, его предали. Стоит ли удивляться, что для дальнейшей политики Николая I были характерны принципиально жесткие и жандармские методы, ставшие неотъемлемой частью созданной императором консервативно-охранительной системы.

Кроме того, под влиянием экстремистских тенденций современности любые другие революционные движения, возникшие после первопроходцев, легко трактуются как антигероические и деструктивные. Не удивительно. Полуграмотный эсер, бросающий бомбы в простых людей, - слишком очевидная параллель в доказательстве деструктивного содержания революционного кружка для общества, живущего болью локальных войн, взрывов в метро и развала СССР. В качестве маленького примера, доказывающего данный тезис, можно привести современный кинематограф, где революционер и террорист очевидный преступник, а часто еще и фанатик. Например, популярная книга и фильм «Статский советник» (автор Б. Акунин, реж. Ф. Янковский, 2005 г.).

Переосмысление истории касается и более далеких (средневековых) исторических событий, которые в силу их эпохальной удаленности более аморфны и мозаичны для нас. Здесь есть поле для ярких научных дискуссий, но нет места острым обывательским эмоциям. Скорее, мы говорим о восприятии легком и 
Ипполитова А.Г

где-то юмористическом. Словно маятник, в истории России меняется отношение к Золотой Орде. Вопрос «Было ли иго?» открыт для каждого поколения. Концепция монголо-татарского ига в привычном стереотипном понимании «господин - раб» не была актуальна для досоветской историографии, а также для историографии русского зарубежья. Да и рассуждения об этом явлении включали много тезисов о взаимовлиянии и межкультурном диалоге. Такая тема была особенно актуальна для евразийцев [16; 17] и военных историков [18]. В повседневном понимании жители Золотой Орды, пестрые в этническом отношении, с трудом воспринимаются как единый этнос, политическая сила и вызывают достаточно большой ассоциативный обывательский ряд. Так, рядовому жителю Казани льстит термин «монголо-татарское иго». Ему невдомек, что булгары тоже имели не самые простые отношения с кочевниками, зато житель Элисты - прямой потомок непосредственно тех, кто правил Ордой, хотя укрепились на нашей территории, перекочевав из Азии лишь в царствование Алексея Михайловича. В спор могут вступить казахи. И так можно продолжать до бесконечности. Для человека, не знакомого с этнологией и этнографией, образ грозного завоевателя является абсолютно перепутанным и некомпетентным. Если иго и было, то хотелось бы понять, кто является прямым потомком «тирана». Но определить в этническом «винегрете» Средневековья и постоянных изменений контуров исторической географии это невозможно. У обычного человека много вопросов, но мало ответов. Поэтому он отшучивается примерно так: «Да все мы немного татары, иго длилось больше двухсот лет», «А пили мы вместе, баб друг у друга воровали» и пр.

В повседневной интеллектуальной реальности прошлого хотелось бы обратить внимание, что исконные древние русские дворянские фамилии не стеснялись и гордились своим «ордынским» происхождением. Хотя уместнее употребить оборот «татарским происхождением». Так понятнее обывателю, хотя «ордынец» с научной позиции звучит корректнее. Ведь татарами ранее называли в принципе огромное количество народов. Это было общее обозначение для наших соседей тюркско-монгольской внешности.

Советская историография безапелляционно утверждала концепцию монголо-татарского ига, сделав фундаментальным основанием труд Н.М. Карамзина, хотя он и не являлся профессиональным историком.

Сегодня мы снова сомневаемся в политическом подчинении Руси. Новое видение о неравноправном политическом союзе нам дал Л.Н. Гумилёв, реанимировавший концепции евразийства.

Было иго или нет - судить очень трудно. В профессиональных научных кругах споры не угаснут, пока не откроются новые убедительные исторические источники. Но восприятие кочевника как врага в современном российском мире однозначно не актуально и смехотворно. Поэтому популярность идеи о союзе логична. Трансформации злого ордынца (наследие советской эпохи) в веселого, хотя и дикого соседа понятны. Сегодня развивается тенденция страха перед деструктивными в нашем ментальном восприятии ценностями Запада, к тому же западный мир агрессивен к россиянам. А кочевники всегда ря- дом. Вдобавок они теперь не просто соседи, но соотечественники, с которыми у нас общие проблемы. В мультиэтничных регионах (Среднее и Нижнее Поволжье, Южный Урал и Сибирь), в мире которых взаимодействие с наследниками Орды никогда не прекращалось, много метисных семей, а наши противоречия носят обывательский, иногда криминальный характер, но не ментальный, как с миром Запада. «Монгол» не воспринимался и не воспринимается как угроза ментальным ценностям. Поэтому взгляды евразийцев, гумилёвцев всегда будут вызывать положительный отклик у части общества. Равно как всегда найдутся и сторонники идеи о монголотатарском иге, особенно в более «русских» и православных регионах (в частности, Золотое Кольцо). Но в любом случае степной мир - наш мир, о чем мы вспоминаем всякий раз, когда российскую культуру пытаются представить враждебной другому миру. Тогда мы начинаем говорить, что русские - другие, особенные, с немного «азиатским» менталитетом. Здесь наш своеобразный спасительный трюк, успокоение. Пусть у нас не все благополучно во внутреннем и внешнем мире, но все равно мы «скифы и азиаты».

Другое эпохальное историческое событие - Великая российская революция 1917 года и Гражданская война - было и остается полигоном битвы на всех социальных уровнях. Слишком оно масштабное и относительно близкое в хронологическом преломлении. Мы по-прежнему в состоянии войны между красными, белыми, зелеными, анархистами и т.д. Одна из причин того - ценности, за которые боролись в период революции и Гражданской войны, попрежнему слишком актуальны, даже обострены.

Можно бесконечно приводить примеры. Но, как представляется автору статьи, примеры, указанные выше, ярче всего заметны, поскольку обнажают такие же проблемы, что и в период их развития. Их острота связана с тем, что те события демонстрируют язвы современности, заставляют проводить параллели, искать в образах, символическом воплощении, а также объективной исторической деятельности ответы на вопросы, которые мучают нас нынешних:

1. Великая Отечественная война - призыв к патриотизму и единству.

2. Рассуждения о революции и вообще бунтовщиках предостерегают от бессмысленных конфликтов, удерживают в мире.

3. Тема монголо-татарского нашествия помогает, как это ни парадоксально, формировать национальное самосознание.

Следует подчеркнуть, что вокруг исторических персоналий трансформационный процесс строится через оценку личности. Нам просто достаточно определить, положительный герой или отрицательный. Деятельность человека интересует во вторую очередь. В качестве примера достаточно привести двух персонажей XX столетия, реформы и политика которых весьма дискуссионны и противоречивы: Николай II, И.В. Сталин (Джугашвили). Однако это не мешает обществу «запустить» процесс сакрализации и давать однозначные оценки, выстраивать стереотип. Так, Николай II причислен Русской православной церковью к лику святых. Для воцерковленных людей, казачества и многих других он стал зна- 
менем мученичества за весь народ, оказавшийся в горниле революционных событий и гражданской войны.

Любой ученый, независимо от концептуальных взглядов и политических симпатий, разводит руками. Человек, допустивший развитие революционных и террористических движений, не умевший принять твердых и однозначных решений для снятия конфликтности в обществе, приблизивший к себе полусектанта Г. Распутина и, наконец, утерявший позиции во внешней политике - святой?! Ответ кроется в его уникальной семейственности и человеческих качества как отца и мужа. Сегодня, когда слово «семья» практически утеряло самоценность, мы наблюдаем аномальные отношения между полами, а дети растут в проблемной ситуации без полноценного родительского воспитания, образ Николая II и его семьи является символом духовности и нравственности во внутриличностных отношениях. Они, действительно, в его биографии строились на основе христианского завета любви к ближнему. Церковь пытается через образ праведного семьянина, доброго отца, любящего супруга призвать общество к сохранению традиционных семейных ценностей. Соответственно, социальные группы, ориентированные на традиционный образ жизни и сохранение идентичности, не замечают полного краха последнего императора как правителя и человека, ответственного за судьбы миллионов.

И.В. Сталину, напротив, трудно отказать в «гиперопеке» над обществом. Как всякий диктатор и тиран, он был способен контролировать любой элемент социальной структуры. По сути, он вывел страну из послереволюционного хаоса, создав на основе новой идеологии мощную империю. Другой вопрос, что личные качества, а также жестокая репрессивная политика делают И.В. Сталина абсолютно бесчеловечным в глазах нескольких поколений. Современники жили в страхе, а затем, в хрущёвский и постсоветский период, с желанием обличать преступления сталинского режима. Еще несколько лет назад мы оценивали генсека глазами А. Солженицына, через призму шаламовских рассказов и т.д. Но сегодня все чаще в СМИ и обывательской культуре наблюдаем комплиментарное отношение к И.В. Сталину. Диктатор трансформировался в героя молодежи, единоличного победителя в Великой Отечественной войне, a репрессии «прощаются», потому что объясняется их практическая макропольза для СССР (подъем экономики, промышленности, рост вооружения и т.д.). Каждый май на автомобилях видим наклейки с портретом вождя и его лозунгами. Такая манифестация у ее носителей демонстрирует патриотическую коннотацию.

Объяснение такой трансформации личности И.В. Сталина очевидна. На фоне безработицы и отсутствия хотя бы каких-то четких ценностных ориентиров для молодежи, все больше растущего недовольства властью, чиновники и политики которой стали символом беспринципного казнокрадства и мздоимства, образ «вождя народов» притягателен. Он не только мог бы объяснить смысл и цели их существования. Это был аскет в самом высоком понимании слова, абсолютно лишенный материальных амбиций и корысти. Сегодня Сталин - знамя честной, трудоспособной и законной власти, которая слу- жит народу. Он добровольно приносит в жертву даже своих родных и вообе личную жизнь на благо государства. Тенденция популярности личности И.В. Сталина достаточно опасная. Именно молодежь готова видеть в настоящем и будущем России аскета-тирана. Значит, готова к экстремальным формам мобилизации ради выхода из управленческого тупика. Вот только два, на мой взгляд, достаточно жестких примера изменения отношений к персоналии под влиянием социокультурной обстановки. Ведь и Николай II, и И.В. Сталин - крайне неоднозначны. Именно признание факта неоднозначности их политики и жизнедеятельности - признак объективности, которая на современном этапе развития социогуманитарного знания отсутствует. Более того, необъективность подкрепляется самыми разными социокультурными манифестациями и символами.

Подытоживая, заметим следующее: наблюдаются трансформации отношения к историческим событиям, фактам и персоналиям в контексте влияния парадигм мышления современной социокультурной обстановки. Общество проводит исторические параллели, оценивает прошлое с позиции понятной им парадигмы мышления, что и приводит к трансформации исторических оценок в различные исторические периоды. Но оценка зачастую основана на историческом опыте, в том числе иррациональном, лежащем в плоскости подсознания, архетипических образов, с одной стороны. С другой - в основе трансформации исторического знания находится конструктивное мифотворчество. Характерно, что мы оцениваем прошлое с позиций современности, чтобы оно продолжало деятельно участвовать в наших судьбах. Здесь история способна проявиться крайне неоднозначно, ее опыт может стать механизмом для достижения узконаправленных целей конкретных социальных слоев.

\section{Список литературы:}

1. Культурология. ХX век. Энциклопедия. Т. 1. СПб.: Университетская книга; ООО «Алетейя», 1998. $447 \mathrm{c}$.

2. Стросс К.-Л. Печальные тропики. М.: АСТ; Астрель, 2010. $441 \mathrm{c.}$

3. Шпенглер О. Закат Европы: Том первый. Образ и действительность. Пер. Н.Ф. Гарелина. М.: Мысль, $1998.663 \mathrm{c}$.

4. Шпенглер О. Закат Европы: Том второй. Очерки морфологии мировой истории. Пер. с нем. и примеч. И.И. Маханькова. М.: Мысль, 1998. 606 с.

5. Данилевский Н.Я. Россия и Европа. Взгляд на культурные и политические отношения славянского мира к германо-романскому. М.: Книга, 1991. 574 с.

6. Гумилёв Л.Н. Этногенез и биосфера земли. М.: Гидрометеоиздат, 1990. 528 с.

7. Гумилёв Л.Н. Конец и вновь начало. М.: Танаис: Ди-Дик, 1994. 541 с.

8. Гуревич А.Я. Споры о главном: Дискуссия о настоящем и будущем исторической науки вокруг французской школы «Анналов». М.: Наука, 1993. 315 с.

9. Marwedel Rainer. Theodor Lessing, 1872-1933: Eine Biographie. Luchterhand, 1987. 446 c.

10. Галкин А. Германский фашизм. М.: Наука, $1989.350 \mathrm{c}$.

11. Мельников Д. Империя смерти: аппарат насилия в нацистской Германии (1933-1945 гг.). М.: Вече, 2000.480 с. 
12. Ипполитова А.Г. Семантика национализма в культурном пространстве современной России. Saarbrucken, Germany: LAP Lambert Academic Publishing, 2011. $160 \mathrm{c}$.

13. Рубцов Ю.В. Штрафные части РККА: правда против вымысла // Вестник Академии военных наук. 2008. № 4 (25). C. 143-147.

14. Капто А.С. Нацизм и «либеральный антисталинизм»: Отпор фальсификаторам истории. М.: ЛИ БРОКОМ, 2011. 655 c.

\section{TRANSFORMATIONS OF HISTORICAL EVENTS AND FACTS ASSESSMENTS IN THE CONTEXT OF SOCIO-CULTURAL INFLUENCE OF MODERNITY}

(C) 2019

Ippolitova Anastasiya Georgievna, candidate of culturology, associate professor, professor of Philosophy and Humanities Department

Samara Law Institute of the Federal Penitentiary Service of Russia (Samara, Russian Federation)

Abstract. The paper shows the transformation of attitudes towards historical events, facts and personalities due to the influence of the thinking paradigms of the modern socio-cultural environment. Objectivity of historical science is a moving thing, because history itself is an organic part of culture, reflecting in its interpretations its mentality and value orientations important for society at a certain period of time. The historical process is a lively cultural stream, filled with unique signs and symbols, ways of demonstration in culture. Modernity determines the attitude of society to the historical process, the importance of personalities and their popularity. Here the historical assessment becomes a reflection of modern realities. We cannot fully feel the influence of the historical character, we can just imagine. We try on the images of the past, fantasize a bit, we give emotions and feelings, «including» the subjectivity of perception of historical events in modern times. The society draws historical parallels, evaluates the «past» from the standpoint of the paradigm of thinking that it understands, which leads to the transformation of historical assessments in different historical periods. All of the above, of course, is characteristic of the transformational process of national history, as shown in a number of examples. They reflect the interpretation characteristic of modern society rather than the position of the author. Particular attention is paid to the assessment of the Great Patriotic War, which is necessary to remember to strengthen the unity of the society and to broadcast patriotic values.

Keywords: history; culture; cultural crisis; objectivity of historical science; historical personality; historical event; sociocultural transformation; myth; mythologization of history; paradigm of thinking; C. Levi-Strauss; T. Lessing; Great Patriotic War; Mongol-Tatars; I.V. Stalin; Nicholas II. 